\title{
Comparative Effect of Latanoprost/Timolol Fixed Combination and Unfixed Combination in Patients with Ocular Hypertension Attending Irrua Specialist Teaching Hospital, Irrua, Nigeria
}

\author{
${ }^{1}$ Ovienria W. A., ${ }^{1}$ Enock M. E., ${ }^{2}$ Akpamu U., ${ }^{3}$ Akhideno P.E., ${ }^{1}$ Momoh N. \\ ${ }^{I}$ Department ofOphthalmology, Irrua Specialist Teaching Hospital, Irrua, Edo State, Nigeria. \\ ${ }^{2}$ Department ofPhysiology, Faculty ofBasic Medical Sciences, College ofMedicine, Ambrose Alli University, \\ Ekpoma, Edo State, Nigeria. \\ ${ }^{3}$ Department ofInternal Medicine, Irrua Specialist Teaching Hospital, Irrua, Edo State, Nigeria.
}

\begin{abstract}
Studies comparing the effect of fixed and unfixed combination of latanoprost and timolol are limited globally and nearly absent among the Nigerian population. This study therefore compares the effect of fixed and unfixed combination of latanoprost and timolol on intraocular hypertension among Nigerian population. The study was a randomized control trial consisting of 102 patients with ocular hypertension who received latanoprost/timolol fixed combination $(n=48)$ and latanoprost/timolol unfixed combination $(n=54)$ for medical reasons. Follow-up visits over 30 weeks was scheduled for 2 weeks from entry date and thereafter every 4 weeks for the remaining 28 weeks making a total of 9 clinic visitations. During the period of the study, the ophthalmologists followed usual care routines and intraocular pressures were recorded while also observing adverse events and evaluating efficacy, safety, tolerability and compliance. Overall, there was $47.73 \%$ reduction of intraocular pressure with fixed combination of latanoprost/timolol as against $43.26 \%$ reduction with unfixed combination. The greatest reduction impacts were observed two weeks after commencing treatment $(-8.27 \mathrm{mmHg}$ and $-5.74 \mathrm{mmHg}$ for fixed and unfixed combinations respectively) and then efficacy reduces progressively for both drugs. This study showed that latanoprost and timolol combinations are effective for intraocular hypertension. However, fixed combination was observed to be more effective compared to unfixed combination at least among Nigerian population.
\end{abstract}

Keywords: Latanoprost; Timolol; Fixed combination; Unfixed combination; Nigerian.

\section{Introduction}

For over 3 decades timolol has been the most popular, effective aqueous suppressant and has been regarded as "gold standard" drug for comparison with other intraocular hypotensive drugs. While it is accepted that pressure less than $18 \mathrm{mmHg}$ retard the progression of glaucoma [1,2], $1 \mathrm{mmHg}$ extra reduction in intraocular pressure in advanced glaucoma is clinically meaningful.In this regards, prostaglandin analog such as latanoprostwas demonstrated to be more effectivein reducing intraocular pressure. In fact, our previous finding justifies this fact among Nigerian population inhabiting the South-South geo-political zones and environs [3].

Of interest is the report that mono-therapy with topical pressure lowering drugs is often inadequate to achieve target pressure in most patients [4,5] and thus, the promotion of combinations of two or more intraocular pressure lowering drugs. The firstattempt on combination therapy was timolol and pilocarpine that successfully reduced the frequency of pilocarpineinstillation without affecting its effectiveness [6]. In ocular hypertension where ocular hypotensive monotherapy do not results to target intraocular pressure (IOP) level, adding a second medication when the original agent showed some effectiveness was recommended [7]. For this reason, Timolol has been combined with various other pressurelowering drugs including prostaglandin analog.While ineffective pressure lowering effect has been reported for some combination treatments[8], adjunctive therapy of latanoprost and timololhas been shown to provide pressure reduction as compared tomonotherapy of the individual drug $[9,10]$.

Of interest in the present study are latanoprost, a prostaglandin F2a analogue that acts by increasing outflow [11,12], and timolol, a beta-adrenergic receptor antagonist that acts by reducing aqueous humor production[13,14]. Thecombination of these two IOP lowering agents has been shown to havean additive effect $[9,10,15,16]$.To the best of our knowledge, thereis no available report on the effectiveness of fixed or unfixedcombinations of timolol and latanoprost in Nigerian population. Moreover, there is paucity of studies comparing the effect offixed and unfixed combination of latanoprost and timolol. Thus, this study is aimed at comparing the pressurelowering effect of fixed and unfixed combination of latanoprost and timolol in theNigerian population. 


\section{Materials And Methods}

2.1. Drug of study:Timolol is a systemic beta-blockers acting as ocular hypotensive by decreasing aqueous secretion. It is the most used topical anti-glaucoma medication, highly available, affordable, and relatively good compliance as it is almost free of ocular side effects. On the other hand, latanoprost is a prostaglandin analogue and act by lowering IOP by increasing uveoscleral aqueous outflow. It is relatively a new class of anti-glaucoma drug with minimal systemic side effects but is expensive especially with reference to economic status of Nigerian inhabitance.

Fixed combination of latanoprost/timolol containing $50 \mathrm{mg}$ of latanoprost and $6.83 \mathrm{mg}$ of timolol maleatein same single bottle was given once daily. While the unfixed combinations of latanoprost $(0.005 \%)$ and timololwere both on separate bottles and weretakenonce daily for latanoprostand twice daily for timolol maleate.

2.2.Study area:The study was a randomized controlled trial study conducted in the Ophthalmic Clinic of Irrua Specialist Teaching Hospital, Irrua, Edo State, South-South, Nigeria. The study was conducted between January 2014 and December 2014.

2.3. Inclusion criteria: Ages between 10 and 80 years, both sexes, no inflammation or rubeotic glaucoma, not allergic to either of the medications, no noticeable or documented side effect to the drug of study. However, patients who are ages $<10$ or $>80$ years, IOP $<21$ or $>50 \mathrm{mmHg}$, any form of surgical intervention, known allergies, requiring other IOP lowering modalities, existing infection or inflammation were excluded. In addition, patients who missed more than 2 clinic visits were also excluded.

2.4. Methods:Once a patient was identified as suitable, the study was explained to the patient and consent to be included in the study obtained. The study was explained to the patients and they were told they can decline and decide to be excluded from the study at any point in time without consequence on the services they received from the clinic.

Before commencement of therapy, patients' initial IOP were measured (Goldmanns' applanation tonometer) and recorded. This served as the control (baseline)value. Group A was placed on timolol maleate ophthalmic solution ( $0.5 \%)$ applied one drop into the lower fornix of each eye at 12-hourly interval. Group B was on latanoprost ophthalmic solution $(0.005 \%)$ applied one drop into the lower fornix of each eye once daily (at night). Patients were enrolled over a period of 12 weeks in the regular clinic setting. Patients for the study were followed-up in 8 clinic visits over a 30 week period. During these periods, their IOP were measured on a two week basis between the hours of $9.00 \mathrm{am}$ and $11.00 \mathrm{am}$ to take into consideration the diurnal variations of IOP. IOP was measured and recorded during each clinic visit.

2.5. Analysis:SPSS (16.0 Version) was used for data entry and analysis. The descriptive statistics conducted and presented in suitable table.

\section{Results}

The results are as presented in table 1,2 and 3. There was no recorded adverse effect in the study subjects that were treated on the combinations used in this study. Table 1 shows the impact of unfixed combination of latanoprost/timolol on IOP for the period of 30 weeks. IOP was observed to reduce progressively with the administration of unfixed combination of latanoprost/timolol. Similarly, table 2 shows the impact of fixed combination of latanoprost/timolol on IOP for a period of 30 weeks. Fixed combination of latanoprost/timolol was observed to bring about a progressive reduction in IOP.

Table 3 is a comparative reduction potential of unfixed and fixed combination of latanoprost/timolol on IOP for the duration of the study. For the study period, unfixed combination latanoprost/timolol resulted in $11.60 \mathrm{mmHg}$ reduction in IOP while fixed combination resulted in a $14.10 \mathrm{mmHg}$ in IOP. Comparatively, this is $43.26 \%$ reduction for unfixed combination as against $47.73 \%$ reduction for fixed combination. IOPs was observed to drop by $-5.74 \mathrm{mmHg}$ for unfixed combination and $-8.27 \mathrm{mmHg}$ for fixed combination in the first two weeks of treatment and the reducing impact reduces for both treatments as the duration of treatment progresses. Overall, for the 30 weeks period there was about $4.47 \%$ difference between fixed and unfixed combinations of latanoprost/timolol. This indicates that fixed combination is $10.33 \%$ more potent than unfixed combination.

Table 1: IOP at Entry and Pattern of Impact of Unfixed Combination of Latanoprost/Timolol

\begin{tabular}{|l|l|l|l|l|l|l|l|l|l|l|}
\hline & Entry & 2 wks & 6 wks & 10 wks & 14 wks & 18 wks & 22 wks & 26 wks & 30 wks \\
\hline $\begin{array}{l}\text { Valid } \\
\text { Number of } \\
\text { Patients }\end{array}$ & 54 & 54 & 54 & 54 & 54 & 54 & 54 & 54 & 54 \\
\hline Missing & 0 & 0 & 0 & 0 & 0 & 0 & 0 & 0 & 0 \\
\hline Mean IOP & 26.80 & 21.06 & 19.13 & 18.09 & 17.20 & 16.31 & 15.87 & 15.46 & 15.20 \\
\hline
\end{tabular}


Table 2: IOP at Entry and Pattern of Impact of Fixed Combination of Latanoprost/Timolol

\begin{tabular}{|l|l|l|l|l|l|l|l|l|l|}
\hline & Entry & 2 wks & 6 wks & 10 wks & 14 wks & 18 wks & 22 wks & 26 wks & 30 wks \\
\hline $\begin{array}{l}\text { Valid Number of } \\
\text { Patients }\end{array}$ & 48 & 48 & 48 & 48 & 48 & 48 & 48 & 46 & 48 \\
\hline Missing & 0 & 0 & 0 & 0 & 0 & 0 & 0 & 2 & 0 \\
\hline Mean IOP & 29.54 & 21.27 & 19.19 & 17.62 & 16.96 & 16.27 & 15.73 & 15.52 & 15.44 \\
\hline
\end{tabular}

Table 3: Comparative Reduction Potential of Unfixed and Fixed Combination of Latanoprost/Timolol on IOP

\begin{tabular}{|l|c|c|}
\hline WEEKS & $\begin{array}{c}\text { Unfixed combination } \\
\text { (latanoprost/timolol in Separate } \\
\text { Bottles) } \\
\text { (IOP in mmHg) }\end{array}$ & $\begin{array}{c}\text { Fixed combination } \\
\text { (latanoprost/timolol in same } \\
\text { bottle) }\end{array}$ \\
\hline $2 \mathrm{wks}$ & 5.74 & 8.27 \\
\hline $6 \mathrm{wks}$ & 1.93 & 2.08 \\
\hline $10 \mathrm{wks}$ & 1.04 & 1.56 \\
\hline $14 \mathrm{wks}$ & 0.89 & 0.67 \\
\hline $18 \mathrm{wks}$ & 0.89 & 0.69 \\
\hline $22 \mathrm{wks}$ & 0.44 & 0.54 \\
\hline $26 \mathrm{wks}$ & 0.41 & 0.21 \\
\hline $30 \mathrm{wks}$ & 0.26 & 0.08 \\
\hline TOTAL & $11.60(43.26 \%)$ & $14.10(47.73 \%)$ \\
\hline
\end{tabular}

\section{Discussion}

This study showed that the combinations of latanoprost/timolol are effective and well tolerated. This is evident in the observed IOP lowering effect and unrecorded adverse outcomes in our study population. This finding is in accordance with the reports of several prospective and randomized clinical trials where the combinations of latanoprost/timolol havedemonstrated effectiveness and tolerability [17-23].

The findings of this study showed that combinations of latanoprost and timolol have a reducing effect on IOP. Comparatively however, fixed combination of latanoprost/timolol has greater impact than unfixed combination. This finding correlates with the theoretical reportedby Shin et al.[22], Higginbotham et al.[21] and Pfeiffer[23]that fixed combination of prostaglandin analog and beta blocker is expected to provide better pressure lowering effect than unfixed combination. This theoretical report was said to indirectly improve the quality of life of glaucoma patients [24,25]. On the contrary, the present finding disagrees with the study by van der Valk et al. [26]who found unfixed combination of latanoprost and timolol to provide better pressure lowering effect compared to fixed combination.

In the present study, fixed combination of latanoprost/timolol was found to have $10.33 \%$ IOP reducing potential than unfixed combination.In glaucoma or ocular hypertension individuals, a fixed-combination formulation was said to be preferred to multidrug regimens in order to maximize patient compliance and quality of life [7]. This may be the reason why fixed combination of latanoprost/timolol showed better reducing IOP capacity compared to unfixed combination where individuals were expected to take from different bottles and twice daily. This assertion is based on the fact that when two drugs are required to controlIOP, there are a number of potential advantages to using a fixedcombination and this was said to includeabsence of risk of drug washout[27],reduced exposure to preservatives, and ultimately better patientcompliance and quality of life[28].

While it has been suggested that patients with high IOP should use more than one ocular hypotensive therapy to reduce IOPs to levels that may be expected to slow or stop disease progression [5], this present study support the combination of fixed IOP hypotensive therapy. Although both fixed and unfixed combinations of ocular hypotensive drugs resulted in similar IOP at the end of 30 weeks, if greater impact is needed in two weeks it is recommended that fixed combination be utilized.

\section{References}

[1]. Liza-Sharmini, A. T., Yuen Shi Yin, N., Shi-Huang Lee, S., Jackson, A. L. and Stewart, W. C. Mean target intraocular pressure and progression rates in chronic angle-closure glaucoma. J Ocul Pharm Ther., 25(1),2009, 71-76.

[2]. The AGIS Investigators. The Advanced Glaucoma Intervention Study (AGIS): 7. the relationship between control of intraocular pressure and visual field deterioration. Am J Ophthalmol; 130: 2000, 429-440.

[3]. Ovienria, W.A., Enock, M.E., Akhideno, P.E., Momoh, N. and Akpamu U.Comparative Efficacy of Timolol and Latanoprost on Intraocular Hypertension Among Patients Attending the Ophthalmic Clinic of Irrua Specialist Teaching Hospital, Irrua, Nigeria. Journal of Pharmacy and Biological Sciences, 2016; Volume 11, Issue 5 Ver. III: 15-18.

[4]. Mosavi, A.A.S., Wang, C.T., Yaakub, A., Zaid, N.A., Tajudin, L.A. Pressure lowering effect of fixed combination and unfixedcombination of latanoprost and timolol in Asian population. Clinical Medicine Research,1(1), 2012, 7-12

[5]. Kass, M.A., Heuer, D.K., Higginbotham, E.J., et al. The Ocular Hypertension Treatment Study: a randomized trial determines that topical ocular hypotensive medication delays or prevents the onset of primary open-angle glaucoma. Arch. Ophthalmol.; 120: 2002, 701-713.

[6]. Høvding, G. \& Aasved, H. Timolol/pilocarpine combination eye drops in open angle glaucoma and inocular hypertension. Acta Ophthalmologica, 65(5), 1987, 594-601. 
[7]. European Glaucoma Society. Terminology and Guidelines for Glaucoma. European Glaucoma Society; 2014. http://www.eugs.org/eng/EGS_guidelines.asp.

[8]. Backman C, Csenblad N-G. A 6-month randomized, double-masked comparison of fixed combination of lantanoprost and timolol with the individual components, continuing into a 6-month open label safety study of fixed combination in patients with glaucoma or ocular hypertension. A multicenter study in Germany. Pharmacia and Upjohn Report, 1994, c0013595.

[9]. Rulo AH, Greve EL, Hoyng PF. Additive effect of lantanoprost, a prostaglandin F2 alpha analogue, and timolol in patients with elevated intraocular pressure. Br J Ophthalmol, 1994; 78: 899-902.

[10]. Lee PY, Shao H, Camras CB, Podos SM: Additivity of prostaglandin F2 alpha-1-isopropyl ester to timolol in glaucoma patients. Ophthalmology, 1991, 98:1079-1082.

[11]. Xalacom®. Summary of Product Characteristics. Electronic Medicines Compendium 2007 [http://emc.medicines.org.uk/medicine/7735/SPC/ Xalacom+eye+drops\% 2c+solution/], Accessed November 16, 2009.

[12]. Toris CB, Gabelt BT, Kaufman PL: Update on the mechanism of action of topical prostaglandins for intraocular pressure reduction. Surv Ophthalmol, 53(Suppl 1), 2008, S107-120.

[13]. Coakes RL, Brubaker RF: The mechanism of timolol in lowering intraocular pressure in the normal eye. Arch Ophthalmol, 96: 1978, 2045-2048.

[14]. Zimmerman TJ, Harbin R, Pett M, Kaufman HE: Timolol and facility of outflow. Invest Ophthalmol Vis Sci, 16: 1977, 623-624.

[15]. Bucci MG, Italian Lantanoprost Study Group: Intraocular pressure-lowering effects of lantanoprost monotherapy versus lantanoprost or pilocarpine in combination with timolol: a randomized, observer-masked multicenter study in patients with openangle glaucoma. J Glaucoma, 8: 1999, 24-30.

[16]. Alm A, Widengård I, Kjellgren D, Söderström M, Friström B, Heijl A, Stjernschantz J: Lantanoprost administered once daily caused a maintained reduction of intraocular pressure in glaucoma patients treated concomitantly with timolol. Br J Ophthalmol, 79: $1995,12-16$

[17]. Schwenn O, Heckmann B, Guzy C, Miller PJ. Long-term effect of latanoprost/timolol fixed combination in patients with glaucoma or ocular hypertension: A prospective, observational, non-interventional study.BMC Ophthalmology.2010;10:21.

[18]. Diestelhorst M, Larsson LI, European-Canadian Lantanoprost Fixed Combination Study Group: A 12-week, randomized, doublemasked, multicenter study of the fixed combination of lantanoprost and timolol in the evening versus the individual components. Ophthalmology, 113: 2006, 70-76.

[19]. Diestelhorst M, Larsson LI, European Lantanoprost Fixed Combination Study Group: A 12 week study comparing the fixed combination of lantanoprost and timolol with the concomitant use of the individual components in patients with open angle glaucoma and ocular hypertension. Br J Ophthalmol, 88, 2004, 199-203.

[20]. Higginbotham EJ, Olander KW, Kim EE, Grunden JW, Kwok KK, Tressler CS, United States Fixed-Combination Study Group: Fixed-combination lantanoprost/timolol vs individual components for POAG or ocular hypertension: a randomized, double-masked study. Arch Ophthalmol, 128:2010, 165-172.

[21]. Higginbotham EJ, Feldman R, Stiles M, Dubiner H, Fixed Combination Investigative Group: Lantanoprost and timolol combination therapy vs monotherapy: one-year randomized trial. Arch Ophthalmol, 120, 2002a,915-922. Higginbotham EJ, Feldman R, Stiles M, et al. Lantanoprost and timolol combination therapy versus monotherapy. Arch Ophthalmol., 120:2002b,915-922.

[22]. Shin D, Feldman RM, Sheu WPS. Efficacy and safety of the fixed combinations lantanoprost/timolol versus dorzolamide/timolol in patients with elevated intraocular pressure. Ophthalmology, 111: 2004, 276-282.

[23]. Pfeiffer N, European Latanoprost Fixed Combination Study Group: A comparison of the fixed combination of lantanoprost and timolol with its individual components. Graefes Arch Clin Exp Ophthalmol, 240, 2002a, 893-899. Pfeiffer N. The German Lantanoprost Fixed Combination Study Group. A comparison of the fixed combination of lantanoprost and timolol with its individual components. Graefes Arch Clin Exp Ophthalmol., 240, 2002b, 893-899.

[24]. Patel SC, Spaeth GL. Compliance in patients prescribed eye drops for glaucoma. Ophthalmic Surg, 26: 1995, $233-236$.

[25]. Kass, M., Gordon, M., Morley Jr, R., Meltzer, D. \& Goldberg, J. Compliance with topical timolol treatment. Am J Ophthalmol, 103(2), 1987, 188.

[26]. van der van der Valk, R., Webers, C. A. B., Schouten, J. S. A. G., Zeegers, M. P., Hendrikse, F. and Prins, M. H. Intraocular Pressure-Lowering Effects of All Commonly Used Glaucoma Drugs:: A Meta-analysis of Randomized Clinical Trials. Ophthalmology; 112(7), 2005, 1177-1185.

[27]. Chrai SS, Makoid MC, Eriksen SP, Robinson JR. Drop size and initial dosing frequency problems of topically applied ophthalmic drugs. J Pharm Sci.;63, 1974, 333-338.

[28]. Dunker S, Schmucker A, Maier H. Tolerability, quality of life, and persistency of use in patients with glaucoma who are switched to the fixed combination of lantanoprost and timolol. Adv Ther., 24: 2007, 376-386. 